\title{
Socioeconomic, demographic and nutritional factors associated with maternal weight gain in general practices in Southern Brazil
}

\author{
Fatores socioeconômicos, demográficos e \\ nutricionais associados com ganho de peso \\ gestacional em unidades básicas de saúde no Sul \\ do Brasil
}

\author{
Michele Drehmer 1 \\ Suzi Camey 2 \\ Maria Inês Schmidt 1 \\ Maria Teresa Anselmo Olinto 3 \\ Andressa Giacomello 1 \\ Caroline Buss 1 \\ Cristiane Melere 1 \\ Juliana Hoffmann 1 \\ Patricia Manzolli 1 \\ Rafael Marques Soares 1 \\ Silvia Ozcariz 1 \\ Maria Angélica Antunes Nunes 1
}

\footnotetext{
1 Programa de Pós-

graduação em Epidemiologia

Universidade Federal do Rio Grande do Sul, Porto Alegre,

Brasil.

2 Departamento de Estatística, Universidade Federal do Rio Grande do Sul, Porto Alegre, Brasil

3 Programa de Pós-graduação em Saúde Coletiva,

Universidade do Vale dos

Sinos, São Leopoldo, Brasil.

Correspondence

M. Drehmer

Programa de Pós-graduação em Epidemiologia, Faculdade de Medicina, Universidade Federal do Rio Grande do Sul. Rua Ramiro Barcelos 2600, 4 andar, sala 419, Porto Alegre, RS 90035-003, Brasil. migdrehmer@gmail.com
}

\begin{abstract}
In order to describe adequacy of weight gain during pregnancy and its association with pre-pregnancy nutritional status and other factors, a cohort study of pregnant women enrolled at 16-36 weeks of gestation and followed up until delivery was carried out in prenatal care in primary care services in Rio Grande do Sul State, Brazil. Maternal weight was recorded at each prenatal care visit. Weight gain was classified as "adequate," "insufficient" or "excessive" (Institute of Medicine). Poisson regression was used to measure the associations. The sample was comprised of 667 women, and insufficient and excessive weight gain incidences were $25.8 \%$ and $44.8 \%$, respectively. Overweight and obese before pregnancy had a significant increased risk of excessive weight gain in pregnancy (RR: 1.75; 95\%CI: 1.48-2.07, RR: 1.55; 95\%CI: 1.23-1.96, respectively). Women with fewer than six prenatal visits had a $52 \%$ increased risk for weight gain below recommended values. Although insufficient weight gain may still be a public health problem, excessive gain is becoming a concern that needs immediate attention in prenatal care.
\end{abstract}

Pregnancy; Weight Gain; Nutritional Status; Maternal Nutrition

\section{Introduction}

Pre-pregnancy nutritional status is a strong determinant of pregnancy weight gain and has a direct influence on obstetric outcomes ${ }^{1}$. Women with low pre-pregnancy weight have twice the chance of having low-weight infants 2 . A prospective study conducted in Brazil showed that women who were obese and overweight before pregnancy were more likely to have diabetes mellitus, preeclampsia and macrosomia during pregnancy 3; while other studies have shown that women who are obese before conception have a higher risk of hypertension, gestational diabetes, induced labor, cesarean delivery, late fetal death, macrosomia, low Apgar scores, infant trauma and child obesity ${ }^{4,5,6}$.

Pregnancy weight gain is associated with maternal and fetal health as it may influence gestational age at birth, mode of delivery, birth weight, and maternal weight retention after delivery. An evaluation of such an index is essential for decision making in public health 7,8,9.

Maternal weight gain that is below recommended levels is associated with low birth weight, prematurity, longer hospital stay and, consequently, higher health-related costs. Excessive weight gain, on the other hand, is associated with a higher incidence of macrosomia, cesarean delivery and child obesity 10,11,12,13.

Pregnancy weight gain determinants include socio-demographic features, parity, smoking, 
pre-pregnancy nutritional status, and caloric intake. There remains a lack of information to relate dietary intakes to gestational weight gain even though it is a primary determinant of weight gain in non-pregnant individuals 14 . The gestational period is a critical part of life, in which nutrient intake should be higher 10 .

There are few studies conducted in developing countries investigating the association between socio-demographic factors and maternal nutrition, more specifically between nutritional status, food intake and weight gain during pregnancy $8,15,16$. It is important to understand these factors as determinants of gestational weight gain if weight gain guidelines for women during pregnancy are to be revised.

The present study aims at measuring the adequacy of the total pregnancy weight gain and investigating its association with pre-pregnancy body mass index, caloric intake, socio-demographic and clinical factors. Therefore, observed results will serve as theoretical background for further application of an early nutritional intervention in pregnant women, in order to provide better obstetric outcomes in this social context.

\section{Method}

\section{Study design and population}

The Study of Food Intake and Eating Behavior in Pregnancy (ECCAGE) is a prospective cohort study of pregnant women followed until the puerperium. 780 pregnant women $(n=780)$ between their $16^{\text {th }}$ and $36^{\text {th }}$ gestational weeks were invited to participate in the study, 68 (8.6\%) of whom refused to participate. Baseline measures were carried out in 18 primary care units located in poor neighborhoods in two cities in the State of Rio Grande do Sul (Porto Alegre and Bento Gonçalves), Brazil, between June 2006 and April 2007. Thus, the final baseline sample comprised 712 women. For gestational weight gain analysis, women were excluded when their weight was not registered until the 28th gestational week, when they were younger than 14 years old, when it was a multiple pregnancy, and when the delivery occurred before the $34^{\text {th }}$ week of pregnancy. Accordingly, 45 (5.7\%) women were excluded, leaving 667 pregnant women for the analysis.

This study was approved by the Research Ethics Committees of the Federal University of Rio Grande do Sul, Murialdo School Health Center, and Municipal Health Departments of Porto Alegre and Bento Gonçalves. Informed consent was signed by all women who agreed to participate.

\section{Sample size}

Figure 1 shows the sample distribution of the 780 pregnant women that were consecutively included. Refusals and losses accounted for $8.6 \%$ and $5.7 \%$ of women respectively; these were excluded. Thus, the final analysis of pregnancy weight gain was conducted with 667 participants.

Based on the relationship between pregnancy weight gain and caloric intake, a sample of 512 women would be needed to detect a number of a 3.32 odds ratio (95\% confidence interval - $95 \% \mathrm{CI}$ : 1.81-6.02) of increased caloric intake, assuming $34 \%$ incidence of excessive weight gain 17 . This sample size was calculated for $\alpha=5 \%$ and statistical power of $90 \%$.

\section{Data collection}

Individual interviews were held in two follow-up waves. The first was during pregnancy and the second was in the immediate postpartum period. Participants were consecutively selected in the waiting room of the prenatal care units before the prenatal visit between their $16^{\text {th }}$ and $36^{\text {th }}$ gestational weeks. Interviews were conducted by trained interviewers in a private setting. At this point, weight and height were measured, caloric intake was evaluated using a food frequency questionnaire, and a further questionnaire was conducted containing socio-demographic information and questions on pre-gestational weight, whether the pregnancy had been planned or not, family income, smoking in pregnancy, and alcohol consumption. Nutritional guidance during pregnancy was also investigated using the following question: "Did you have nutritional orientation during prenatal care?”. Interviews were conducted by six trained interviewers.

Follow-up data were collected in the immediate postpartum period. Information on delivery date and birth place was obtained by direct contact with the participant. Additional data regarding all prenatal visits, including weight, gestational age and ultrasounds were obtained through access to medical records.

\section{Gestational weight gain}

Total weight gain was calculated by the difference between the weight at the end of pregnancy obtained from medical records, and pre-pregnancy weight reported by participants at baseline. Final pregnancy weight was considered as the last weight recorded at least two weeks before delivery. For pregnant women who had no such weight record, values were attributed using the simple imputation method, adopting the first 


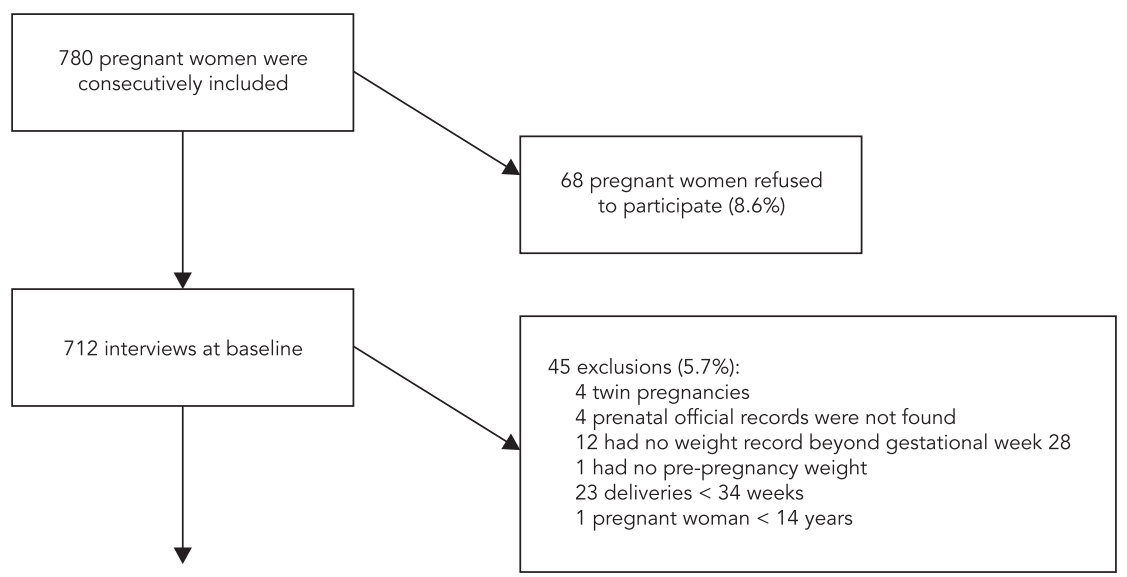

Prenatal follow-up

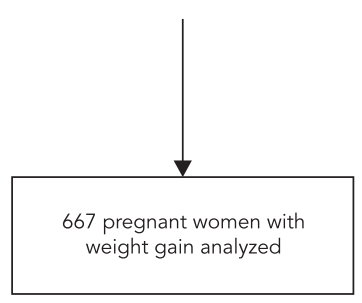

weight recorded from the $2^{\text {nd }}$ trimester as the basal component. The basal component was the pre-pregnancy weight in only seven women. Imputation of final weight was calculated based on the following equation:

$$
F W=L R W+M W W G \times N M W
$$

where: $F W=$ final weight; $L R W=$ last recorded weight; $M W W G$ = mean weekly weight gain; and $N M W=$ number of missing weeks.

Mean weekly weight gain was estimated as:

$$
M W W G=\frac{L R W-F R W}{G A \_L R W-G A \_F R W}
$$

where: $F R W=$ first recorded weight from the $2^{\text {nd }}$ trimester; $G A \_L R W=$ gestational age of last recorded weight; and $G A \_F R W=$ gestational age corresponding to the first weight recorded at the $2^{\text {nd }}$ trimester.

Number of missing weeks was estimated as:

$$
N M W=G A \_D-G A \_L R W
$$

where: $G A \_D=$ gestational age at delivery.
Imputation of missing data on weight at the end of pregnancy was performed on $19.1 \%$ of the sample.

Total weight gain was classified according to the recommendation of the Institute of Medicine (IOM) ${ }^{14}$. Total weight gain between 12.5 and $18 \mathrm{~kg}$ was considered adequate for women with pre-pregnancy body mass index (BMI) below $18.5 \mathrm{~kg} / \mathrm{m}^{2}$, between 11.5 and $16 \mathrm{~kg}$ for women with pre-pregnancy BMI between 18.5 and $24.9 \mathrm{~kg} / \mathrm{m}^{2}$, and between 7 and $11.5 \mathrm{~kg} / \mathrm{m}^{2}$ for women with pre-pregnancy BMI between 25 and $29.9 \mathrm{~kg} / \mathrm{m}^{2}$. Total weight gain between 5 and $9 \mathrm{~kg}$ was considered appropriate when pre-pregnancy BMI was higher than or equal to $30 \mathrm{~kg} / \mathrm{m}^{2}$.

\section{Gestational age}

Gestational age was calculated using the ultrasound estimation provided the exam was performed no later than the $20^{\text {th }}$ week of gestation. For participants whose ultrasounds were carried out after week 20 , gestational age was calculated 
using the mean between age estimated by ultrasound and age calculated by last menstruation. For those who did not have an ultrasound, gestational age was calculated only from the reported date of last menstruation.

\section{Daily caloric intake}

Data on food intake were collected through an 88-item Food Frequency Questionnaire (FFQ), derived from a previously validated questionnaire 18 and validated for this population. The questionnaire provided standard servings of each food item to assess the amount consumed during pregnancy 19 .

Estimates of energy intake, based on the FFQ, were obtained by programming the software SPSS for Windows (SPSS Inc., Chicago, U.S.A.), using the following equation: calories consumed per day $=$ (number of servings consumed) $\mathrm{x}$ (frequency of consumption) $\mathrm{x}$ (nutrient content of the food serving), using Brazilian food composition tables as a reference 20,21. The recommended energy intake for pregnant women based on the Dietary Reference Intakes 22 was not employed due to the fact that the FFQ tends to overestimate calorie consumption. The reference values that were used originated from the data of the current study. The cut off points for adequate consumption were obtained from the limits of the $95 \%$ CI of the caloric intake of pregnant women who had a BMI of between 18.5 and $24.9 \mathrm{~kg} / \mathrm{m}^{2}$ at early pregnancy and who gained weight within recommended values. This was set to determine the variation interval of energy intake considered adequate for this sample. Therefore, the variable "energy intake" was evaluated in three categories: $800-2,778.9 \mathrm{kcal} /$ day, between $2,778.9$ and $3,098.8 \mathrm{kcal} /$ day, and 3,098.8 - 4,800kcal/day. Adequate energy intake ranged between 2,778.9 and $3,098.8 \mathrm{kcal} /$ day, and the other categories refer to energy intake below or above this interval.

For the analysis that included caloric intake, 97 women (12.4\%) were excluded because their reported daily energy intake fell outside the usually accepted pregnancy range of $800 \mathrm{kcal}$ $(3,347 \mathrm{~kJ})$ to $4,800 \mathrm{kcal}(20,083 \mathrm{~kJ})$, based on IOM 10,23 recommendations, as applied in previous studies $24,25,26,27$.

\section{Statistical analysis}

Data were described as means, standard deviations (SD) and percentages (\%). Linear-by-Linear Association chi-square test $\left(\chi^{2}\right)$ was used to test the association between pre-pregnancy BMI and weight gain. Analyses were performed using two Poisson regression models with robust variance. In the first model, the outcome variable was dichotomized into insufficient weight gain versus adequate and excessive weight gain; in the second model, it was dichotomized into excessive weight gain versus adequate and insufficient weight gain. Independent variables tested included maternal age, years of schooling, family income, number of children, gestational age at birth, planned pregnancy, pre-pregnancy BMI, number of prenatal visits, smoking, alcohol consumption, nutritional guidance, and daily caloric intake.

Those associations that resulted in $\mathrm{p}<0.20$ in the unadjusted analyses were included, step by step, in multiple Poisson regression models. The final model was the one with the lowest Akaike Information Criterium (AIC) corrected for a finite sample.

The significance level was set at $5 \%$ for all tests. Confidence intervals were $95 \%$. The software programs used were SPSS v. 16 and R version 2.4.1 (The R Foundation for Statistical Computing, Vienna, Austria; http://www.r-project.org).

\section{Results}

Sociodemographic, nutritional, behavioral and dietary characteristics of the sample of 667 women are described in Table 1. Gestational age was evaluated by ultrasound before week 20 in 365 women $(54.7 \%)$, by the mean of ultrasound above week 20 and date of last menstruation in 153 women (23\%), and using date of last menstruation only in 149 participants (22.3\%).

Mean total pregnancy weight gain was $13.9 \mathrm{~kg}$ ( \pm 6.5). Weight variation during pregnancy ranged from $-7 \mathrm{~kg}$ to $38.4 \mathrm{~kg}$, and weight loss was reported by 13 women $(2.1 \%)$. Of those women whose weight was lower at the end of pregnancy than at the beginning $(n=13), 30.7 \%(n=4)$ were considered overweight, and $69.2 \%(n=9)$ obese. Among 667 pregnant women with weight gain analyzed, the percentages with insufficient and excessive maternal weight gain were 25.8 and $44.8 \%$, respectively, according to the IOM classification. Table 2 showed incidences of pregnancy weight gain according to the categories of prepregnancy BMI. Women who started pregnancy with low pre-pregnancy BMI $\left(<18.5 \mathrm{~kg} / \mathrm{m}^{2}\right)$ had a higher proportion of insufficient weight gain $(\mathrm{p}<$ 0.001). On the other hand, women who had BMI of between 25 and $29.9 \mathrm{~kg} / \mathrm{m}^{2}$ at early pregnancy had higher proportions of excessive weight gain, which occurred in $66.2 \%$ of them $(p<0.001)$. In addition, $81.1 \%$ of pregnant women who had pre-pregnancy obesity had inappropriate weight gain, either excessive or insufficient. 
Table 1

Socio-demographic, clinical and dietary characteristics of pregnant women receiving care at Primary Care Services in Southern Brazil, $2007(n=667)$.

\begin{tabular}{|c|c|c|c|}
\hline Variables & Mean (SD) & $\mathrm{n}$ & $\%$ \\
\hline Age (years) & $25(6.4)$ & & \\
\hline$\leq 19$ & & 162 & 24.3 \\
\hline $20-29$ & & 330 & 49.5 \\
\hline$>30$ & & 175 & 26.2 \\
\hline Years of schooling & $7.6(2.7)$ & & \\
\hline $0-4$ & & 92 & 13.8 \\
\hline $5-8$ & & 327 & 49.0 \\
\hline$\geq 9$ & & 248 & 37.2 \\
\hline Family income * & $2.6(1.9)$ & & \\
\hline Number of children & $1.0(1.3)$ & & \\
\hline \multicolumn{4}{|l|}{ Planned pregnancy } \\
\hline No & & 415 & 62.2 \\
\hline Yes & & 252 & 37.8 \\
\hline Pre-pregnancy BMI $\left(\mathrm{kg} / \mathrm{m}^{2}\right)$ & $24.25(4.7)$ & & \\
\hline$<18.5$ & & 26 & 3.9 \\
\hline $18.5-24.9$ & & 414 & 62.1 \\
\hline $25.0-29.9$ & & 148 & 22.2 \\
\hline$>30.0$ & & 79 & 11.8 \\
\hline Number of visits & $7.6(2.7)$ & & \\
\hline$\leq 6$ & & 227 & 34.0 \\
\hline $7-9$ & & 287 & 43.0 \\
\hline$\geq 10$ & & 153 & 22.9 \\
\hline \multicolumn{4}{|l|}{ Smoking during pregnancy } \\
\hline No & & 529 & 84.1 \\
\hline Yes & & 138 & 20.7 \\
\hline \multicolumn{4}{|l|}{ Alcohol use during pregnancy } \\
\hline No & & 561 & 84.1 \\
\hline Yes & & 106 & 15.9 \\
\hline \multicolumn{4}{|l|}{ Received nutritional guidance } \\
\hline No & & 387 & 58.0 \\
\hline Yes & & 280 & 42.0 \\
\hline Calories (kcal/day) *夫 & $2,838(911)$ & & \\
\hline $800.0-2,778.9$ & & 283 & 49.6 \\
\hline $2,778.9-3,098.8$ & & 76 & 13.3 \\
\hline$>3,098.8$ & & 211 & 37.0 \\
\hline
\end{tabular}

BMI: body mass index.

* Minimum wages;

** $n=570$, because we excluded women with caloric intake $<800 \mathrm{kcal}$ and $>4,800 \mathrm{kcal}$.

Table 3 shows univariate Poisson regression analyses with robust variance for outcomes of insufficient pregnancy weight gain and excessive pregnancy weight gain, as well as sociodemographic, nutritional and dietary variables. Insufficient weight gain was associated with a higher number of factors than excessive weight gain. Insufficient weight gain was significantly asso- ciated with pre-pregnancy BMI, maternal age, family income, planned pregnancy and number of prenatal visits. Significant associations for excessive weight gain with pre-pregnancy BMI and number of prenatal visits were observed.

Table 4 shows the final models for insufficient and excessive weight based on multivariate Poisson regressions with robust variance. Asso- 
Incidence of total pregnancy weight gain according to pre-pregnancy body mass index (BMI) of women receiving care at Primary Care Services in Southern Brazil, 2007 ( $n=667)$.

\begin{tabular}{|c|c|c|c|c|c|c|c|c|}
\hline \multirow[t]{3}{*}{ Pre-pregnancy BMI (kg/m²) } & \multirow[t]{3}{*}{$\mathbf{N}$} & \multirow[t]{3}{*}{$\%$} & \multicolumn{6}{|c|}{ Pregnancy weight gain * } \\
\hline & & & \multicolumn{2}{|c|}{ Insufficient } & \multicolumn{2}{|c|}{ Adequate } & \multicolumn{2}{|c|}{ Excessive } \\
\hline & & & $\mathrm{n}$ & $\%$ & $\mathrm{n}$ & $\%$ & $\mathbf{n}$ & $\%$ \\
\hline$<18.5$ & 26 & 3.9 & 12 & 46.2 & 11 & 42.3 & 3 & 11.5 \\
\hline $18.5-24.9$ & 414 & 62.0 & 123 & 29.7 & 138 & 33.3 & 153 & 37.0 \\
\hline $25.0-29.9$ & 148 & 22.2 & 18 & 12.2 & 32 & 21.6 & 98 & 66.2 \\
\hline$>30.0$ & 79 & 11.8 & 19 & 24.1 & 15 & 19.0 & 45 & 57.0 \\
\hline
\end{tabular}

${ }^{\star} p<0.001$, Linear-by-Linear Association test.

ciations were similar to those of the univariate analyses in terms of magnitude and direction of associations. Compared to women with normal weight before pregnancy those who had BMI of between 25 and $29.9 \mathrm{~kg} / \mathrm{m}^{2}$ in early pregnancy had a $58 \%$ lower risk of insufficient weight gain during pregnancy; compared to the same reference group, having pre-pregnancy BMI lower than $18.5 \mathrm{~kg} / \mathrm{m}^{2}$ was not a risk factor for insufficient weight gain. Women with fewer than six prenatal visits had a $52 \%$ greater risk of weight gain below recommended values compared to the remaining women (Table 4).

Those who started pregnancy as overweight had a $75 \%$ increased risk (95\%CI: 1.48-2.07) of excessive weight gain during pregnancy compared to the reference category. Pre-pregnancy obesity increased by $55 \%$ the risk of excessive weight gain by the end of pregnancy compared to the reference category. Women who had BMI below $18.5 \mathrm{~kg} / \mathrm{m}^{2}$ in early pregnancy had a $69 \%$ lower risk of excessive weight gain than the reference category. Pregnant women who had fewer prenatal visits ( $\leq 6$ visits) had a lower risk of excessive weight gain, compared to the remaining ones.

\section{Discussion}

The results observed in the present study point to relevant aspects of maternal nutrition by emphasizing improper pregnancy weight gain among women receiving care in Primary Care Services. For most categories of pre-pregnancy body mass index, the incidence of excessive or insufficient weight gain was high. Results also pointed to the existence of two paradoxes. First, having few prenatal visits is a risk factor for insufficient weight gain, and a protective factor against excessive weight gain. Secondly, starting pregnancy with overweight or obesity proved to be a risk for excessive weight gain, but having low pre-pregnancy BMI was not a risk for insufficient weight gain during pregnancy.

Among women with pre-pregnancy obesity, the vast majority $(81.1 \%)$ showed inappropriate weight gain, either insufficient $(24.1 \%)$ or excessive $(57.0 \%)$. The incidence of excessive weight gain, found in $44.8 \%$ of the sample, is close to that found in a survey of weight gain records during pregnancy in five American states from 1990 to 1996, whose percentage of excessive weight gain in American-Hispanic women was $39 \% 28$. The incidence of weight gain below recommended values was $25.8 \%$, higher than that of Hispanic women and pregnant women from the United States among whom the incidence of insufficient weight gain during pregnancy was $22 \%$ and $16 \%$, respectively 29,30 . Brazilian studies on pregnant women in the primary health network found $38 \%$ and $36.5 \%$ of insufficient weight gain, and $29 \%$ and $29.1 \%$ incidence of excessive weight gain in 1995 and 2001, respectively 15,16. A prospective study with 173 pregnant women and their newborns monitored at a primary health care in Rio de Janeiro in 2007 found high prevalences of insufficient and excessive gestational weight gain and only $36.4 \%$ of the women studied found themselves within the IOM recommended levels ${ }^{31}$.

In the present study, excessive weight gain was more frequent in women who were overweight prior to pregnancy. This is a reason for concern due to the possibility of increased obesity in women at reproductive age. Similar results were found in North America. In a sample of 622 pregnant women being followed in Primary Care Services in the USA, the risk of excessive weight gain in women who started pregnancy with BMI between 26 and $29 \mathrm{~kg} / \mathrm{m}^{2}$ was 
Univariate Poisson regression with robust variance between maternal weight gain and socio-demographic, clinical and dietary characteristics of pregnant women receiving care at Primary Care Services in Southern Brazil, $2007(n=667)$.

\begin{tabular}{|c|c|c|c|c|}
\hline \multirow[t]{3}{*}{ Variables } & \multicolumn{4}{|c|}{ Weight gain } \\
\hline & \multicolumn{2}{|c|}{ Insufficient } & \multicolumn{2}{|c|}{ Excessive } \\
\hline & Crude RR & p-value & Crude RR & $\mathrm{p}$-value \\
\hline \multicolumn{5}{|c|}{ Pre-pregnancy BMI (kg/m²) } \\
\hline$<18.5$ & $1.55(1.00-2.41)$ & 0.05 & $0.31(0.12-0.91)$ & 0.033 \\
\hline $18.5-24.9$ & 1.00 & - & 1.00 & - \\
\hline $25.0-29.9$ & $0.41(0.26-0.64)$ & $<0.001$ & $1.79(1.51-2.12)$ & $<0.001$ \\
\hline$>30.0$ & $0.81(0.53-1.23)$ & 0.323 & $1.54(1.22-1.94)$ & $<0.001$ \\
\hline \multicolumn{5}{|l|}{ Age (years) } \\
\hline$\leq 19$ & $1.37(1.02-1.85)$ & 0.036 & $0.92(0.74-1.13)$ & 0.433 \\
\hline $20-29$ & 1.00 & - & 1.00 & - \\
\hline$>30$ & $1.05(0.76-1.45)$ & 0.755 & $0.99(0.81-1.22)$ & 0.993 \\
\hline \multicolumn{5}{|l|}{ Years of schooling } \\
\hline $0-4$ & $1.45(0.98-2.15)$ & 0.063 & $0.86(0.65-1.14)$ & 0.316 \\
\hline $5-8$ & $1.34(0.99-1.80)$ & 0.053 & $0.91(0.77-1.10)$ & 0.357 \\
\hline$\geq 9$ & 1.00 & - & 1.00 & - \\
\hline Family income * & $0.92(0.85-0.99)$ & 0.033 & $1.02(0.98-1.06)$ & 0.342 \\
\hline Number of children & $1.05(0.91-1.23)$ & 0.481 & $0.99(0.89-1.09)$ & 0.878 \\
\hline \multicolumn{5}{|l|}{ Planned pregnancy } \\
\hline No & $1.32(1.00-1.76)$ & 0.049 & $0.93(0.78-1.10)$ & 0.416 \\
\hline Yes & 1.00 & - & 1.00 & - \\
\hline \multicolumn{5}{|c|}{ Number of prenatal visits } \\
\hline$\leq 6$ & $1.57(1.22-2.02)$ & $<0.001$ & $0.66(0.54-0.81)$ & $<0.001$ \\
\hline$>6$ & 1.00 & - & 1.00 & - \\
\hline \multicolumn{5}{|c|}{ Smoking during pregnancy } \\
\hline No & 1.00 & - & 1.00 & - \\
\hline Yes & $1.08(0.79-1.48)$ & 0.595 & $1.04(0.85-1.27)$ & 0.678 \\
\hline \multicolumn{5}{|c|}{ Alcohol use during pregnancy } \\
\hline No & 1.00 & - & 1.00 & - \\
\hline Yes & $1.11(0.88-156)$ & 0.513 & $0.77(0.58-1.00)$ & 0.058 \\
\hline \multicolumn{5}{|c|}{ Received nutritional guidance } \\
\hline No & $1.19(0.91-1.55)$ & 0.200 & $1.07(0.84-1.19)$ & 0.935 \\
\hline Yes & 1.00 & - & 1.00 & - \\
\hline \multicolumn{5}{|c|}{ Daily caloric intake $(\mathrm{kcal} /$ day $) * *(n=570)$} \\
\hline$<2,778.9$ & $0.92(0.62-1.38)$ & 0.714 & $1.05(0.78-1.39)$ & 0.74 \\
\hline $2,778,9-3,098.8$ & 1.00 & & & \\
\hline$>3,098.8$ & $0.73(0.50-1.19)$ & 0.244 & $1.07(0.80-1.44)$ & 0.631 \\
\hline
\end{tabular}

BMI: body mass index.

* Minimum wages;

** Because we excluded women with caloric intake $<800 \mathrm{kcal}$ and $>4,800 \mathrm{kcal}$.

4.97 (95\%CI: 2.70-9.30) times higher than that of pregnant women who were eutrophic 32 .

Where the amount of prenatal visits was below the recommended number of six, this proved to be a risk factor for insufficient weight gain. Current nutritional assistance in prenatal care prioritizes maternal weight gain, discouraging restrictive diets and weight loss during pregnancy. Therefore, the focus of prenatal assistance is insufficient weight gain in order to prevent lowweight births 1 . This helps explain the finding that fewer prenatal visits might be a protective factor 
Multiple Poisson regression with robust variance of pregnant women receiving care at Primary Care Services in Southern Brazil, $2007(n=667)$.

\begin{tabular}{|c|c|c|c|c|}
\hline \multirow[t]{3}{*}{ Variables } & \multicolumn{4}{|c|}{ Weight gain } \\
\hline & \multicolumn{2}{|c|}{ Insufficient * } & \multicolumn{2}{|c|}{ Excessive ** } \\
\hline & $\begin{array}{l}\text { RR adjusted } \\
\qquad(95 \% \mathrm{Cl})\end{array}$ & $p$ value & $\begin{array}{l}\text { RR adjusted } \\
(95 \% \mathrm{Cl})\end{array}$ & $p$ value \\
\hline \multicolumn{5}{|c|}{ Pre-pregnancy BMI (kg/m²) } \\
\hline$<18.5$ & $1.52(0.97-2.41)$ & 0.068 & $0.31(0.10-0.92)$ & 0.035 \\
\hline $18.5-24.9$ & 1.00 & - & 1.00 & - \\
\hline $25.0-29.9$ & $0.42(0.26-0.66)$ & $<0.001$ & $1.75(1.48-2.07)$ & $<0.001$ \\
\hline$>30.0$ & $0.79(0.52-1.21)$ & 0.289 & $1.55(1.23-1.96)$ & $<0.001$ \\
\hline \multicolumn{5}{|c|}{ Number of prenatal visits } \\
\hline$\leq 6$ & $1.52(1.18-1.95)$ & 0.001 & $0.67(0.55-0.82)$ & $<0.001$ \\
\hline$>6$ & 1.00 & - & 1.00 & - \\
\hline
\end{tabular}

BMI: body mass index.

* Adjusted for maternal age, maternal schooling level, family income, planned pregnancy and gestational age at birth;

** Adjusted for maternal age, alcohol consumption in pregnancy and gestational age at birth.

for excessive weight gain. There seems to be less attention to excessive weight gain, especially in women with overweight and obesity as there is no maximum limit for adequate weight gain. Finally, the possibility of residual confusion should also be considered, that is, other socioeconomic factors that were not evaluated in this study may be associated since pregnant women in less favorable conditions have fewer prenatal visits and have a higher incidence of pre-pregnancy low weight 33 .

Another intriguing finding in this study indicates that being overweight or obese prior to pregnancy is a risk factor for excessive weight gain, but having low pre-pregnancy BMI is not a risk factor for insufficient weight gain during pregnancy. The latter finding may result from the traditional emphasis on insufficient weight gain to prevent low birth weight infants. Regarding the former finding, pregnant women with excessive weight before pregnancy may not receive orientation to prevent excessive weight gain. Under this hypothesis prenatal care may give greater attention to fetal rather than maternal health.

Excessive pregnancy weight gain should be considered a public health problem. It is estimated that, of all cases of obesity during the postpartum period, about $70 \%$ are due to excessive weight gain during pregnancy 34 . Pregnancy is, therefore, a risk period for the development of obesity in women of a fertile age. A Brazilian cohort of pregnant women followed for nine months after delivery confirms that pregnancy weight gain should be systematically monitored in prenatal care to prevent future obesity and associated chronic diseases 16 .

Limitations of this study include a single measurement of daily caloric intake during pregnancy: the research covered a broad time interval (between weeks 16 and 36), with the possibility of having a great variability of food intake between the second and third trimester of pregnancy. $71.2 \%$ of samples $(n=475)$ were taken during the second trimester and $28.8 \%(n=192)$ in the third. Another possible limitation was the imputation of values for weights at the end of pregnancy in $19.1 \%$ of the sample, although the proportion of the sample in which imputation was used was lower than that used in another study (24.5\%) that applied the same methodology 35 . Reported pre-pregnancy weight was also used, which was supported by a strong correlation with measured weight, shown in previous studies on Brazilian pregnant women $(r=0.92)^{36}$. Finally, different sources of secondary data were used, collected from official records to obtain information regarding the prenatal period.

Evaluation and management of excessive weight gain in individuals, especially in those with unfavorable socioeconomic conditions, have proven to be a hard task. Although there are guidelines for prenatal care issued by the Brazilian Ministry of Health, the management of weight gain during pregnancy seems to have been overlooked by health professionals 37 . Due to the main focus on the infant and on insuffi- 
cient maternal weight gain that causes low birth weight, risks resulting from a pregnancy with excessive weight gain and further weight excess in women may not be properly considered.

This study can contribute to a better understanding of the weight gain pattern in pregnant women receiving care in Primary Care Services and its associated factors, adjusted for caloric intake. Knowledge of this reality may allow for the development of public policies relative to weight control. Such actions may result in improvement in prenatal care and, consequently, in the health of this population, with guidance on eating habits even before conception, as pre-pregnancy body mass index is the main determinant of weight gain during pregnancy.

\section{Resumo}

Para caracterizar o ganho ponderal gestacional e sua associação com estado nutricional pré-gestacional e fatores relacionados à gravidez, realizou-se estudo de coorte com gestantes arroladas consecutivamente entre a $16 \underline{a}$ e a $36 \underline{a}$ semanas, e seguidas até o parto em serviços da rede básica de saúde do Estado do Rio Grande do Sul, Brasil. Informações do peso da gestante em cada consulta de pré-natal foram obtidas. Ganho de peso foi classificado conforme o Instituto de Medicina dos Estados Unidos. Regressão de Poisson com variância robusta foi utilizada. Incidências de ganho de peso insuficiente e excessivo das 667 gestantes foram de 25,8\% e 44,8\%, respectivamente. Gestantes com sobrepeso e obesidade pré-gestacional apresentaram risco para ganho ponderal excessivo (RR: 1,75; IC95\%: 1,48-2,07 e RR: 1,55; IC95\%: 1,23-1,96). Gestantes com menos de seis consultas de pré-natal tiveram risco de $52 \%$ de ganhar peso insuficiente. Embora o ganho ponderal insuficiente persista como um problema de saúde pública, o ganho excessivo está se configurando como uma questão que precisa de atenção imediata nos serviços de pré-natal.

Gravidez; Ganho de Peso; Estado Nutricional; Nutrição Materna
The increased epidemic of obesity and evidence relating maternal nutrition with the occurrence of chronic disease in adulthood 38 , in addition to a high incidence of excessive weight gain during pregnancy should be considered as a public health problem. Weight gain and maternal nutrition should be constantly monitored in primary care services and indexes of maternal and fetal health should also be considered due to their strong correlation with obstetrical outcomes.

\section{Contributors}

M. Drehmer carried out the research and wrote the article. R. M. Soares, A. Giacomello, C. Melere, S. Ozcariz, J. Hoffmann, C. Buss, and P. Manzolli carried out the research and reviewed the article. M. I. Schmidt contributed to the study design and article write up. S. Camey worked on the data analysis and reviewed the manuscript. M. A. A. Nunes coordinated the study, provided orientation for the analysis, data interpretation, and reviewed the manuscript. M. T. A. Olinto reviewed the manuscript.

\section{Acknowledgments}

The research was financed by the Programa de Apoio a Núcleos de Excelência (PRONEX) and Coordenação de Aperfeiçoamento de Pessoal de Nível Superior (CAPES). The authors thank Dr. Andréa Poyastro Pinheiro for her valuable comments on this manuscript. 


\section{References}

1. Committee on the Impact of Pregnancy Weigh on Maternal and Child Health/National Research Council/Institute of Medicine. Influence of pregnancy weight on maternal and child health: workshop report. Washington DC: National Academies Press; 2007.

2. Ronnenberg AG, Wang X, Xing H, Chen C, Chen D, Guang W, et al. Low preconception body mass index is associated with birth outcome in a prospective cohort of Chinese women. J Nutr 2003 133:3449-55.

3. Nucci LB, Schmidt MI, Duncan BB, Fuchs SC, Fleck ET, Santos Britto MM. Nutritional status of preg nant women: prevalence and associated pregnancy outcomes. Rev Saúde Pública 2001; 35:502-7.

4. American Dietetic Association. Position of the American Dietetic Association: nutrition and lifestyle for a healthy pregnancy outcome. J Am Diet Assoc 2002; 102:1479-90.

5. Cnattingius S, Bergstrom R, Lipworth L, Kramer MS. Prepregnancy weight and the risk of adverse pregnancy outcomes. N Engl J Med 1998; 338: 147-52.

6. Villamor E, Cnattingius S. Interpregnancy weight change and risk of adverse pregnancy outcomes: a population-based study. Lancet 2006; 368 : 1164-70.

7. Kleinman KP, Oken E, Radesky JS, Rich-Edwards JW, Peterson KE, Gillman MW. How should gestational weight gain be assessed? A comparison of existing methods and a novel method, area under the weight gain curve. Int J Epidemiol 2007; 36:1275-82.

8. Seligman LC, Duncan BB, Branchtein L, Gaio DS Mengue SS, Schmidt MI. Obesity and gestational weight gain: cesarean delivery and labor complications. Rev Saúde Pública 2006; 40:457-65.

9. Ministério da Saúde. Guia alimentar para a população brasileira: promovendo a alimentação sau dável. Brasília: Ministério da Saúde; 2006.

10. Institute of Medicine. Nutrition during pregnancy. Washington DC: National Academy Press; 1990.

11. Frederick IO, Williams MA, Sales AE, Martin DP, Killien M. Pre-pregnancy body mass index, gestational weight gain, and other maternal characteristics in relation to infant birth weight. Matern Child Health J 2007; 12:557-67.

12. Abrams B, Altman SL, Pickett KE. Pregnancy weight gain: still controversial. Am J Clin Nutr 2000; 71(5 Suppl):1233S-41S

13. Stotland NE, Hopkins LM, Caughey AB. Gestational weight gain, macrosomia, and risk of cesarean birth in nondiabetic nulliparas. Obstet Gynecol 2004; 104:671-7.

14. Institute of Medicine. Nutrition during pregnancy. Washington DC: National Academies Press; 2009.

15. Nucci L, Duncan B, Mengue S, Branchtein L, Schmidt M, Fleck E. Assessment of weight gain during pregnancy in general prenatal care services in Brazil. Cad Saúde Pública 2001; 17:1367-74.
16. Kac G, Benicio MH, Velasquez-Melendez G, Va lente JG, Struchiner CJ. Gestational weight gain and prepregnancy weight influence postpartum weight retention in a cohort of Brazilian women. J Nutr 2004; 134:661-6.

17. Olafsdottir AS, Skuladottir GV, Thorsdottir I, Hauksson A, Steingrimsdottir L. Maternal diet in early and late pregnancy in relation to weight gain Int J Obes (Lond) 2006; 30:492-9.

18. Sichieri R, Everhart JE. Validity of a Brazilian food frequency questionnaire against dietary recalls and estimated energy intake. Nutr Res 1998; 18:1649-59.

19. Giacomello A, Schmidt M, Nunes M, Duncan B Soares R, Manzolli P, et al. Validation of a food frequency questionnaire conducted among pregnant women attended by the Brazilian National Health Service in the two municipalities of the State of Rio Grande do Sul, Brazil. Rev Bras Saúde Matern Infant 2008; 8:445-54

20. Philippi ST. Tabela de composição de alimentos: suporte para decisão nutricional. São Paulo: Coronário; 2002

21. Núcleo de Estudos e Pesquisas em Alimentação, Universidade Estadual de Campinas. Tabela brasileira de composição de alimentos. Versão II. 2a Ed. Campinas: Núcleo de Estudos e Pesquisas em Alimentação, Universidade Estadual de Campinas; 2006.

22. Food and Nutrition Board, Institute of Medicine. Dietary reference intakes for energy, carbohydrate, fiber, fat, fatty acids, cholesterol, protein, and amino acids. Washington DC: National Academies Press; 2005

23. Forsythe HE, Gage B. Use of a multicultural food-frequency questionnaire with pregnant and lactating women. Am J Clin Nutr 1994; 59(1 Suppl):203S-6.

24. Azevedo DV, Sampaio HA. Consumo alimentar de gestantes adolescentes atendidas em serviço de assistência pré-natal. Rev Nutr 2003; 16:273-80.

25. Freisling H, Elmadfa I, Gall I. The effect of socioeconomic status on dietary intake, physical activity and Body Mass Index in Austrian pregnant women. J Hum Nutr Diet 2006; 19:437-45.

26. George GC, Hanss-Nuss H, Milani TJ, FreelandGraves JH. Food choices of low-income women during pregnancy and postpartum. J Am Diet Assoc 2005; 105:899-907.

27. Watts V, Rockett H, Baer H, Leppert J, Colditz G. Assessing diet quality in a population of low-income pregnant women: a comparison between Native Americans and whites. Matern Child Health J 2007; 11:127-36.

28. Schieve LA, Cogswell ME, Scanlon KS. Trends in pregnancy weight gain within and outside ranges recommended by the Institute of Medicine in a WIC population. Matern Child Health J 1998; 2:111-6.

29. Schieve LA, Cogswell ME, Scanlon KS. An empiric evaluation of the Institute of Medicine's pregnancy weight gain by race. Obstet Gynecol 1998; 91: 878-84. 
30. May R. Prepregnancy weight, inappropriate gestational weight gain, and smoking: relationships to birth weight. Am J Hum Biol 2007; 19:305-10.

31. Rodrigues PL, Oliveira LC, Brito AS, Kac G. Determinant factors of insufficient and excessive gestational weight gain and maternal-child adverse outcomes. Nutrition; in press.

32. Olson CM, Strawderman MS. Modifiable behavioral factors in a biopsychosocial model predict inadequate and excessive gestational weight gain. J Am Diet Assoc 2003; 103:48-54.

33. Coimbra L, Figueiredo F, Silva A, Barbieri MA, Bettiol H, Caldas AJ, et al. Inadequate utilization of prenatal care in two Brazilian birth cohorts. Braz J Med Biol Res 2007; 40:1195-202.

34. Siega-Riz AM, Evenson KR, Dole N. Pregnancy-related weight gain: a link to obesity? Nutr Rev 2004; 62(7 Pt 2):S105-11.
35. Brawarsky P, Stotland NE, Jackson RA, FuentesAfflick E, Escobar GJ, Rubashkin N, et al. Pre-pregnancy and pregnancy-related factors and the risk of excessive or inadequate gestational weight gain. Int J Gynaecol Obstet 2005; 91:125-31.

36. Oliveira AF, Gadelha AMJ, Leal MC, Szwarcwald CL. Estudo da validação das informações de peso e estatura em gestantes atendidas em maternidades municipais no Rio de Janeiro, Brasil. Cad Saúde Pública 2004; 20 Suppl 1:S92-100.

37. Ministério da Saúde. Vigilância alimentar e nutricional - SISVAN. Orientações básicas para a coleta, o processamento, a análise de dados e a informação em serviços de saúde. Manual técnico. Brasília: Ministério da Saúde; 2004.

38. Wu G, Bazer FW, Cudd TA, Meininger CJ, Spencer TE. Maternal nutrition and fetal development. J Nutr 2004; 134:2169-72.

Submitted on 29/Aug/2009

Final version resubmitted on 24/Mar/2010

Approved on 29/Mar/2010 